\title{
Serving Readers in a Special International Library
}

The IAEA library is presented and some of the characteristics of its users are noted. Emphasis is given to the method in which the library is introduced to these users with the objective of enabling them to use the tools and collections as independently as possible. The initial interview, the preparation of a Field-of-Interest Register, and a personalized UDC schedule are explained.

$\mathrm{T}$

HE TYPES OF PROBLEMS faced by an international library in serving its readers are, in general, not much different from those encountered by a library in a national organization. They vary, however, considerably in degree because of the greater differences among the backgrounds of its users. The International Atomic Energy Agency has, at the present time, ninety-seven member states from whom personnel are recruited for the secretariat. Thus, there are scientists from all the regions of the world including large countries and small ones, as well as those that are old and those that are new. Some expect very little in the way of library services, while others take it for granted that they will continue to receive the same type of service they obtained at home from their library in a large research center of a highly developed country.

The IAEA library contains, as present, over thirty-two thousand bound volumes and ninety-one thousand technical reports and receives about eleven hundred periodicals. It is a depository library for the U.S. Atomic Energy Commission,

Mr. Kepple is Officer-in-Charge of the International Atomic Energy Agency library in Vienna. and it maintains a large collection of documents issued by the United Nations and other international organizations. It is housed in the agency's headquarters building along the Kaerntner Ring in Vienna. Its present staff numbers eighteen from six member states. Although its collection emphasizes nuclear energy and its applications, its holdings reflect the widening range of the agency's interests by including material on law, economics, medicine, agriculture and biology.

Not only does the library provide service for the technical personnel, but it also has a large collection of mimeographed documents from the United $\mathrm{Na}$ tions, other international organizations, and the agency itself. A very active reference service is conducted for the agency's administrative personnel based on this material. A special law library also has been created for the use of the agency's legal division.

Included among the readers served by the library are those not connected with the agency but who nevertheless have a legitimate need for its facilities. These include students, teachers, writers and scientists living in Vienna. Although the collection cannot compete with those of some of its neighbors which date back for centuries, it is reasonably complete 
and current in its areas of specialization. Its quarters are modern and comfortable, and to the students especially open stack access is a convenience they do not ordinarily enjoy. Usage by this group is rapidly increasing as the word gets around.

This latter is perhaps the aspect of the library which surprises the most people. All collections-books, reports, periodicals, and microfiche-are available for direct consultation by the library user. Furthermore, the library never closes, and at night and on weekends, when no one is in attendance, instructions are displayed explaining how one may charge an item out to himself. This is incomprehensible to some users, and the inevitable question is: "But does not this cause you to have terrible losses?" When it is explained that the losses are negligible and the missing items usually turn up later anyway, they shake their heads in amazement, and one individual replied with candor: "That would never work in my country!"

As would be expected, the periodical literature and the major indexing and abstracting journals are equally well known to all of the scientists. In the field of nuclear energy, however, one abstracting journal is regarded with particular favor by users: Nuclear Science $A b$ stracts, which because of its coverage of the report literature and because it provides a single source for all material in this field, is highly regarded, well known, and much used by almost everyone regardless of nationality. Two sets are maintained, one in the reports library and one in the reference section. The reports themselves are filed by their alphanumeric numbers, and NSA is relied upon for subject and author retrieval.

Although the majority of the clerical staff of the agency are Austrians and are more or less permanent, there is a rapid turnover among the professional members of the agency's secretariat. Many stay for only two or three years and very few for more than five. This presents certain difficulties for the library, particularly with the journal literature. Professor A, from country X, may request a group of journals in his subject field. Five years later, just when respectable runs are starting to develop, he leaves and is replaced by Professor B from country $\mathrm{Y}$ who requires an entirely different group. Since space in Vienna's busy First District is at a premium, the situation would soon lead to serious difficulties. Therefore, efforts are made to stabilize the collection with the major journals, in all languages and in each of the agency's subject fields, and grow only with the new journals (which is enough of a problem in itself). All major backruns are obtained only as microfiche. To supplement relatively small holdings, there is a large collection of abstracting and indexing journals. Since there are many good libraries in Vienna from whom the library can borrow, almost any article can usually be obtained within twenty-four hours.

Language differences do not present any particular problem. English is the working language of the agency, and those few who do not speak it when they come soon learn. Although the agency has four official languages, English, French, Russian, and Spanish, and is located in a German-speaking country, most of the material in the library is written in English, with Russian second. This is especially true of the book collection, where an effort was made initially to represent all languages as equitably as possible. Experience has shown, however, that except for major reference works, the use of non-English books is limited. This is partly due to the position of English as a universal scientific language and partly because the periodicals and reports are used by some of the non-English speaking countries in preference to books, for the scientific litera- 

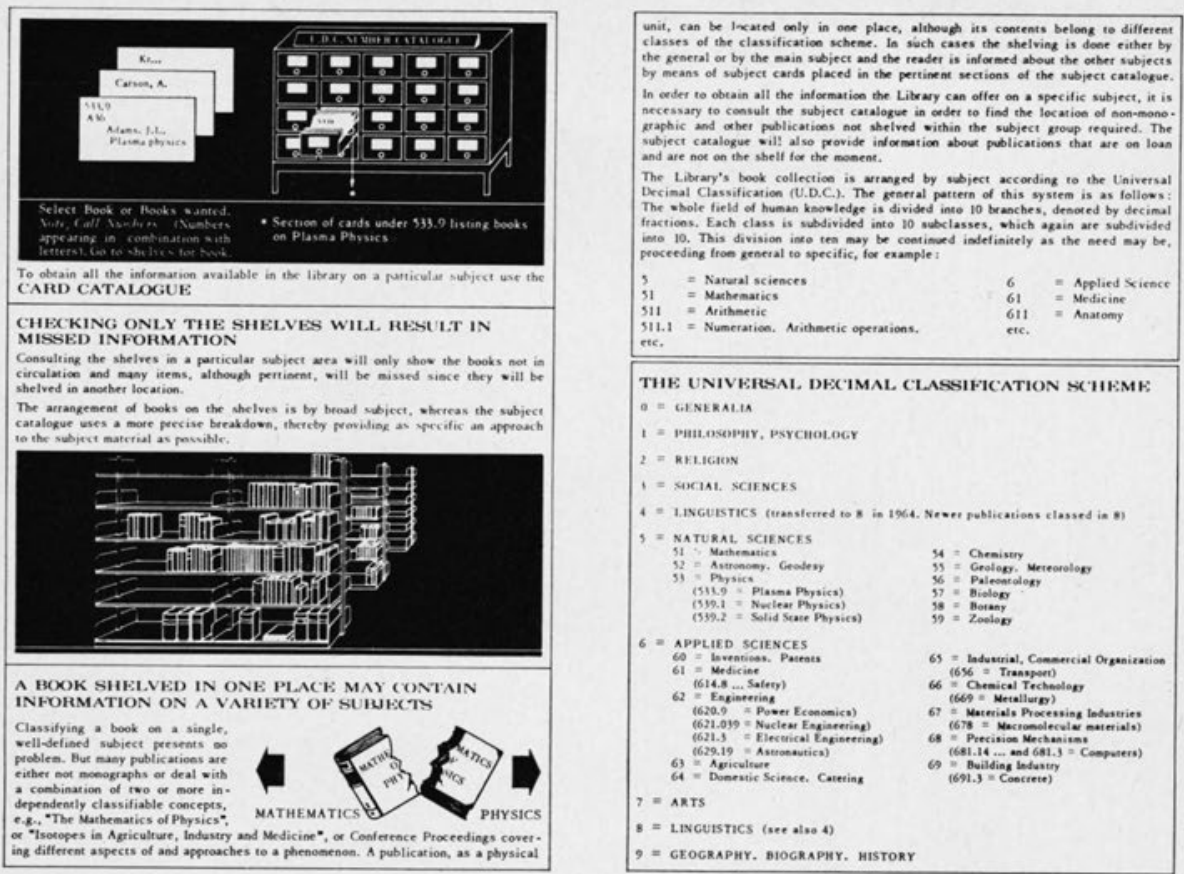

FIG. 1.-Folder in which personal UDC schedule is inserted.

ture. It is interesting for librarians to note that during a training course held for library personnel, some of the professional staff presenting parts of the course preferred to do so in English, although their mother tongue was German. They felt that the terminology of library science is so English-oriented that many terms could not readily be translated.

\section{INTRODUCING THE NEW EMPLOYEE TO THE LIBRARY}

As soon as possible after his arrival in Vienna, the new agency employee will be contacted by a library staff member and a time will be arranged for them to meet in the library for an interview. During this interview, he is given a tour of the library and the various collections are explained. He is shown how to use the card catalog, the abstracting and indexing tools, and how to find material in the report and microfiche collections. He is presented with a map of the library, a directory of its services, and a publication explaining how to use its various components. He is introduced to other library staff members with whom he may have dealings.

So that the library can obtain the information it needs, part of the interview is devoted to learning as much as possible about the scientific background of the employee; his training, education, degrees, interests, languages, specialization and the particular subject interests of his present work. He is then given a list of subject headings prepared by the library which lists all subjects relating to the work of the agency. He is asked to check those headings dealing with his work and scientific interests. The information obtained during the interview and from the headings checked, is then used in two ways:

1. Field of Interest Register. This includes all members of the agency's scientific secretariat and is arranged in two 


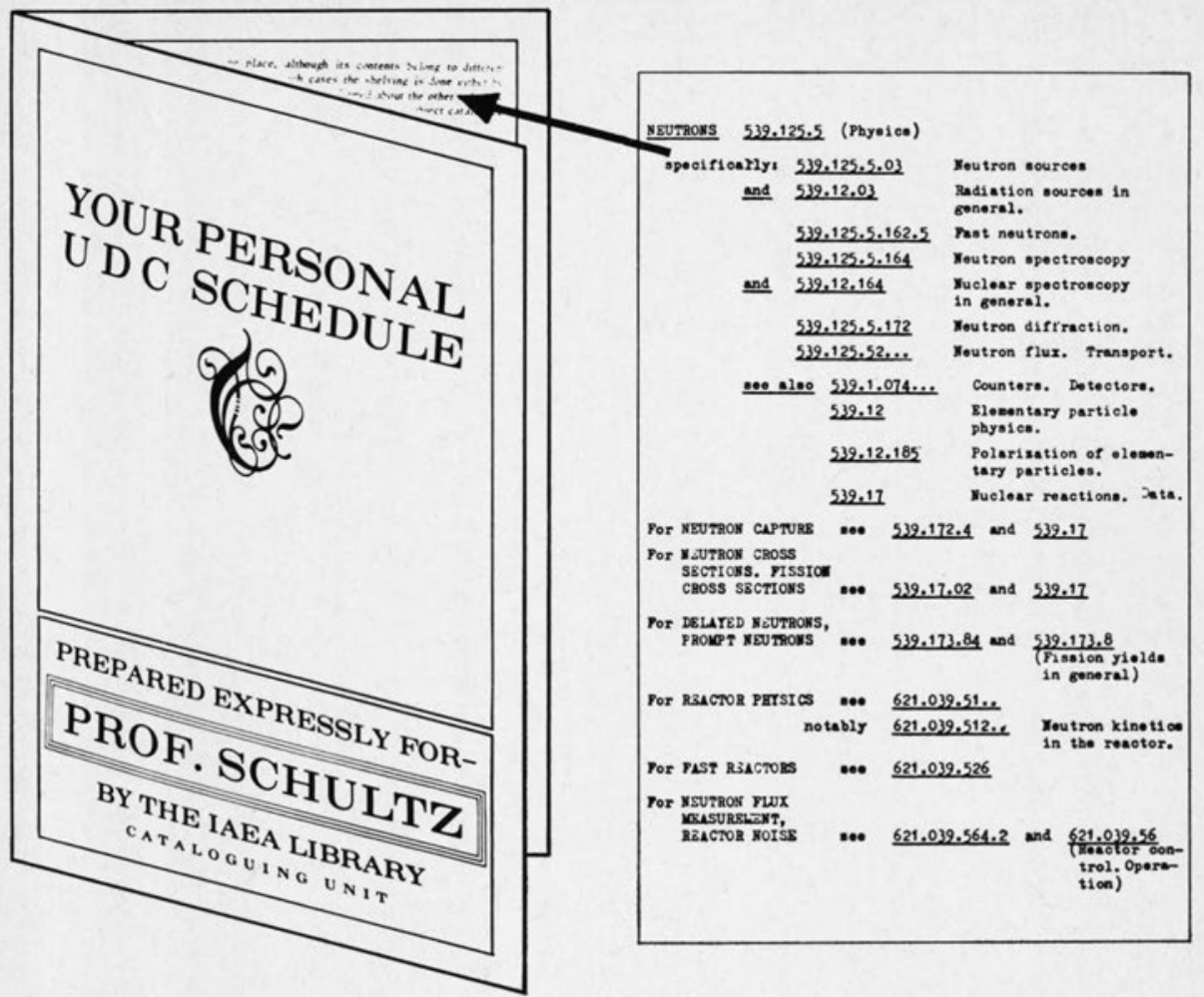

Fig. 2.-Typical personal UDC schedule.

parts. Part I consists of cards, arranged alphabetically by the name of the individual. Under each person's name, one can learn of his fields of study, his degrees, languages, and subjects of major interest. Part II contains subject cards arranged alphabetically. On each subject card is listed the names of those persons working or interested in that field.

This register was set up initially by interviewing every member of the agency's professional staff. It is now kept upto-date through the individual interviews held with each new staff member.

Although one could refer to this register as a simplified SDI system, it is used for this purpose only incidentally. In an organization where the personnel are continually changing and the interests are ever expanding, it is necessary to have such a register for an efficient acquisitions program. Proper advice can be obtained for purchasing new periodicals, reference works, and any material not directly related to current activities. It is also useful to consult experts when screening the items offered on exchange. Although exchange is a useful method for obtaining many items, one must be careful to refuse those items for which there is no need and which only consume valuable shelf space. The register is also useful as a reference tool. When ordinary sources fail, it is often possible to consult an expert in the field and obtain leads which the library can use or pass on to the requester for him to follow up himself. Finally, the register enables the library to route those mysterious items that are unaccountably re- 
ceived from time to time, to their proper recipients.

When the individual has been added to this register, which is maintained by the reference unit, the list of subject headings is sent to the cataloging unit where a personalized UDC schedule is prepared.

2. Personalized UDC Schedule. Probably the most difficult library tool for the new staff member to learn to use is the card catalog. The author and title sections present no particular problems, but few persons seem interested in solving the complexities of the Universal Decimal Classification, which in the best of circumstances is a difficult classification system for the average library user. However, this classification has a particular advantage to an international library since the subject headings are numbers and the word index can be in as many languages as one wishes.

To promote the UDC number catalog, the cataloging unit has conceived and developed a procedure for providing a personalized UDC schedule for each new staff member. This is compiled from the list of subjects headings prepared during the interview described above. The correct UDC numbers are listed for each heading and cross references are provided. When completed, it is sent to him, and the staff member then has a list of UDC numbers corresponding to those subject fields in which he is particularly interested.

To explain the UDC itself, a folder has been prepared emphasizing that it is not enough to browse in the stacks, pleasant though this may be, but in order not to miss important material (the important items are usually out, anyway) it is necessary to consult the UDC number catalog. The personal schedule is then inserted in the folder and sent to the individual. Figure 1 shows the inside of the folder and Figure 2, the schedule itself ready to be inserted in the folder and sent to the scientist (in this case, Prof. Schultz).

\section{Library Publications}

In addition to the interview, the preparation of the Field of Interest Register, and the UDC schedules described above, the library issues a number of publications which attempt to explain the library to its users. One is a booklet describing the library, its arrangement, and how to obtain material from the book, periodical and report collections. A $5^{\prime \prime}$ × $8^{\prime \prime}$ card listing all library services, their locations, and telephone numbers was prepared and sent to everyone in the agency. The library publishes a monthly Recent Acquisitions List which includes a "column." This is written by a library staff member and describes some particular service, new reference work, a current problem, some future plan, etc. It is hoped that this will give the reader an understanding of some of the inner workings of the library as well as give him information about items that may prove useful in his work.

The new employee is also informed at this time about the regular services that are available to him. These include: automatic journal routing, automatic routing of technical reports in special subject areas, general reference service, literature searches, and photocopying.

Of course, on the basis of a single interview and the distribution of a number of publications, it cannot be expected that every individual will have learned all there is to know in order to use the library efficiently. It is at best an introduction and one can only hope that it will encourage him to return and learn more. It is as yet too early to evaluate the success of this program. It is believed, however, that it is resulting in an increased use of the services available, thereby justifying the effort in-

(Continued on page 216) 
what stronger $\mathrm{B}$ than the latter. The Dismissed averaged $\mathrm{C}+$, confirming the above findings for Drexel.

For both the Pratt and Drexel graduating groups, three-fifths finished within two years of their admission, so they must have been taking at least a half course load each quarter. Since only fourteen Drexel students are still enrolled, this suggests that only a few members of the class have attended Drexel at the rate of only one course at a time and still have a chance to graduate. No Pratt student is still struggling toward the degree. Because the number of Drexel students actually taking only one course at a time during the period was relatively large, however, perhaps one-fourth to one-half of the student body each quarter, the Inactive group apparently included a significant percentage of one-course-at-a-time students. Or, apparently the chances of graduating instead of becoming inactive were much higher if you were a full-time or at least a half-time student than if you took a smaller course load each quarter. In sup- porting this conclusion Rosenhaupt found part-time graduate students at Columbia to have completed fewer course hours and to have had poorer chances of earning degrees than fulltime students, 75 per cent of those earning degrees doing so within two years of entrance, and 90 per cent after three years. ${ }^{11}$

Admissions Problems. A conclusion to be drawn from this study is that admissions procedures for selecting students who would eventually graduate needed improvement in both schools in 1961. With only 44 per cent graduated from Drexel and 54 per cent from Pratt, the dropout rate was high. While a certain percentage of these dropouts were because of low grades, apparently many were not. The schools needed not only to improve techniques of selecting persons qualified to carry out graduate course work successfully but also to choose students who would stay with the program until graduation.

${ }^{11}$ Rosenhaupt, op. cit., p. 37.

\section{. . . International Library}

(Continued from page 207)

volved. It is after all not enough merely to offer good library services. They must be presented to the user in such a way that he can understand their value to him and, furthermore, be able to use them himself. Teaching the reader to use the collection and to take full advantage of the services offered is one of the most important tasks currently facing the special library for, as emphasis is placed increasingly upon the new information systems, the reader must not be forgotten. Regardless of nationality, the needs of individuals are best satisfied when they can help themselves, for they alone know what they really want. The successful library is still the one in which the reader can do this as much as possible. 